\title{
Debate: Why should gender-affirming health care be included in health science curricula?
}

\author{
Elma de Vries ${ }^{1 *} \mathbb{D}$, Harsha Kathard ${ }^{2}$ and Alex Müller ${ }^{3}$
}

\begin{abstract}
Background: Every person who seeks health care should be affirmed, respected, understood, and not judged. However, trans and gender diverse people have experienced significant marginalization and discrimination in health care settings. Health professionals are generally not adequately prepared by current curricula to provide appropriate healthcare to trans and gender diverse people. This strongly implies that health care students would benefit from curricula which facilitate learning about gender-affirming health care.

Main body: Trans and gender diverse people have been pathologized by the medical profession, through classifications of mental illness in the Diagnostic and Statistical Manual of Mental Disorders (DSM) and International Classification of Disease (ICD). Although this is changing in the new ICD-11, tension remains between depathologization discourses and access to gender-affirming health care.

Trans and gender diverse people experience significant health disparities and an increased burden of disease, specifically in the areas of mental health, Human Immunodeficiency Virus, violence and victimisation. Many of these health disparities originate from discrimination and systemic biases that decrease access to care, as well as from health professional ignorance.

This paper will outline gaps in health science curricula that have been described in different contexts, and specific educational interventions that have attempted to improve awareness, knowledge and skills related to genderaffirming health care. The education of primary care providers is critical, as in much of the world, specialist services for gender-affirming health care are not widely available. The ethics of the gatekeeping model, where service providers decide who can access care, will be discussed and contrasted with the informed-consent model that upholds autonomy by empowering patients to make their own health care decisions.

Conclusion: There is an ethical imperative for health professionals to reduce health care disparities of trans and gender diverse people and practice within the health care values of social justice and cultural humility. As health science educators, we have an ethical duty to include gender-affirming health in health science curricula in order to prevent harm to the trans and gender diverse patients that our students will provide care for in the future.
\end{abstract}

Keywords: Transgender, Trans and gender diverse, Health disparities, Pathologisation, Gender-affirming health care, Social justice, Health science education

\footnotetext{
* Correspondence: Elma.devries@uct.ac.za

${ }^{1}$ School of Public Health and Family Medicine, University of Cape Town,

Cape Town, South Africa

Full list of author information is available at the end of the article
}

(c) The Author(s). 2020 Open Access This article is distributed under the terms of the Creative Commons Attribution 4.0 International License (http://creativecommons.org/licenses/by/4.0/), which permits unrestricted use, distribution, and reproduction in any medium, provided you give appropriate credit to the original author(s) and the source, provide a link to the Creative Commons license, and indicate if changes were made. The Creative Commons Public Domain Dedication waiver (http://creativecommons.org/publicdomain/zero/1.0/) applies to the data made available in this article, unless otherwise stated. 


\section{Background}

Every person who seeks health care should be affirmed, respected, understood, and not judged. However, trans and gender diverse (TGD) people have experienced significant marginalization and discrimination in health care settings, as will be described further below. Health professionals are generally not adequately prepared by current curricula to provide healthcare to TGD people and have described feeling "completely out-at-sea" [1]. This strongly implies that healthcare students would benefit from curricula which facilitate learning about gender-affirming health care.

The literature search for this debate started with a key word search of databases including Scopus, Medline, Pubmed and Web of Science during the time period 2017-2018. Search terms included 'trans', 'transgender', 'medical education', 'health science education', 'genderaffirming', 'curriculum' and combinations thereof. A search of article reference lists identified further relevant articles as did personal communication with colleagues. This data informed the main topics for this debate.

Transgender is a term that refers to persons whose gender identity is different to that normatively expected on the basis of assigned sex. Gender diverse is a term to describe "people who do not conform to society's or culture's expectations for men and women" [2]. Nonbinary is a term used for a person who identifies as neither male nor female [3] and gender nonconforming for a person whose gender identity is different to that normatively expected on the basis of assigned sex, "but may be more complex, fluid, multifaceted, or otherwise less clearly defined than a transgender person" [3]. Genderqueer is another term used by some with this range of identities [3]. For this article, trans and gender diverse (TGD) will be used as an umbrella term to include transgender, gender nonconforming, genderqueer and gender diverse people. Cisgender is a term for someone whose gender identity is the same as that normatively expected on the basis of their assigned sex. Genderaffirming health care has been described by Radix, Reisner and Deutch [4] as "health care that holistically attends to transgender people's physical, mental, and social health needs and well-being while respectfully affirming their gender identity". This is more than just transition-related care and refers to an affirming experience in all health care encounters. Gender-affirming care models utilise an approach of depathologisation of human gender diversity (transgender as "identity"), rather than a pathological perspective (transgender as "disorder") [4].

Until recently, little gender-affirming research existed, and, in the literature, TGD people have often been included in the broader grouping LGBT. This acronym combines sexual minority people (lesbian, gay, and bisexual people), and gender minority people (TGD people).
These sexual and gender minority groups have in common that they often experience social exclusion, stigma, discrimination, violence, as well as ignorance from health professionals [5]. These experiences are rooted in societal heteronormativity and cisnormativity that generally marginalises non-heteronormative sexual (LGB) and gender (TGD) identities. Heteronormativity is "the assumption that everyone is heterosexual, and that heterosexuality is superior to all other sexualities" [6]. Cisnormativity is "the assumption all people are cisgender, that those assigned male at birth always grow up to be men and those assigned female at birth always grow up to be women" [7]. This strong normative facilitates transphobia, which is emotional disgust, fear, hostility, violence, anger or discomfort felt or expressed towards people who do not conform to the gender expectations of society [8]. Thus, transphobia has been described as a symptom of heterocis-normativity [9]. Müller comments that "though there is a common source of oppression [hetero-cis-normativity], it has to be acknowledged that this oppression acts on different identities (sexual orientation or gender) in different ways" [10].

Compared to cisgender people, TGD people experience significant health disparities and an increased burden of disease [11]. Many of these health disparities originate from discrimination and systemic biases that decrease access to care, as well as from health professionals' ignorance [12]. It is thus critical to educate health professionals to deliver equitable care for TGD populations, but most health sciences education institutions do not yet provide sufficient education [13].

\section{Brief history of pathologisation, Diagnostic and Statistical Manual of Mental Disorders (DSM) and International Classification of Disease (ICD)}

People with diverse gender identities and expressions have been part of society for millennia. With increasing medical interest in providing transition-related care in the 1950's, the TGD person became a "patient" and with the "medical gaze", diverse gender identities have often been viewed as pathology [14]. The history of pathologisation is important to understand in relation to genderaffirming health care, as there is a tension between pathologisation and access to health care [15].

Historically, medical research produced the "scientific" evidence that pathologized sexualities and gender identities that did not conform to societal expectations, as well as supported treatments such as so-called "conversion therapy" that is now regarded as unethical [15]. Until 1973, homosexuality was listed as a mental illness in the American Psychiatric Association's Diagnostic and Statistical Manual of Mental Disorders (DSM) [16]. Sex between people of the same sex or gender still remains criminalised in 68 United Nations member states 
in 2019 [17]. The DSM is an influential document that is used internationally to diagnose and classify mental illness. Gender diversity remains listed in the DSM until today. In the DSM-4, the term "Gender identity disorder" was used and in DSM-5 this had been changed to "Gender Dysphoria" [18]. The intention of the change in the DSM-5 was to reduce stigma, while ensuring that individuals are able to access the care they need [14]. Proponents for the term "Gender Dysphoria" argued that it was less stigmatizing than "Gender identity disorder" [14]. However, others have pointed out that gender diversity in itself is not pathological, and have questioned the need to medically classify and diagnose gender diversity $[19,20]$.

The International Classification of Disease (ICD) of the World Health Organisation (WHO) is used to code diagnoses and process payment for health care, especially in the private health care sector. It includes diagnoses for all body systems, whereas the DSM only categorises mental illness. In 1975, a diagnosis of "transsexualism" was introduced in the ICD-9 [14], and in the ICD-10, published in 1992, the diagnostic term was changed to "Gender Identity Disorder" [21]. In the ICD-11, this term will be changed to "Gender Incongruence" [22]. It will be relocated from the chapter on Mental and Behavioural Disorders to a new chapter, Conditions Related to Sexual Health. On 18 June 2018, the WHO published a version of ICD-11, with the press release stating "While evidence is now clear that it is not a mental disorder, and indeed classifying it in this way can cause enormous stigma for people who are transgender, there remain significant health care needs that can best be met if the condition is coded under the ICD" [23]. The ICD-11 was adopted at the World Health Assembly on 25 May 2019, for implementation in 2022 [24]. While such a diagnostic classification might be needed in order to access gender-affirming treatment, it is the view of many TGD activists and groups that it can further pathologize and stigmatise TGD identities [10, 25]. Although a strong argument has been made towards depathologisation, including in Southern Africa [19], some in the Southern African TGD community have also raised concerns regarding the depathologisation movement [26]. McLachlan [26] argues that "the African context may be more sympathetic towards a person who has a diagnosis and is identified as having a mental condition than a person who diverges from what is seen and/or constructed as the norm". This remains a controversial topic with many different perspectives, ranging from no diagnostic category at the one end of the spectrum, to the middle ground of a diagnosis of "gender incongruence" in a separate chapter in the ICD-11, to retention as a mental health diagnosis as in the current DSM-V. Tensions continue to exist over how to classify "gender incongruence" to both depathologize gender diversity expressions and identities, while ensuring access to gender-affirming health care [15]. Regardless of if or how gender incongruence is classified within (or without) medical classification systems, TGD people have the right to receive health care that is affirming, respectful and non-judgmental, for which health professionals play a crucial role.

\section{Do TGD people experience gender-identity related health disparities?}

Social determinants of health (SDOHs) are defined by the WHO as "the conditions in which people are born, grow, live, work and age" and that are "shaped by the distribution of money, power and resources." [27]. Pega and Veale argue for the recognition of gender identity as a SDOH [28]. "Prejudice, stigma, transphobia, discrimination, and violence targeted at TGD people produce differential levels of social exclusion for populations defined by gender identity, including in health care settings. These social conditions disadvantage TGD people through social exclusion and privilege cisgender people through social inclusion, resulting in differential health outcomes. So, although gender identity in itself does not determine health, it socially stratifies the population into differential exposures to SDOHs such as transphobia". This can be compared to other social stratifiers such as race or ethnicity, which are also considered SDOHs [28].

The health disparities are not inherent to TGD individuals but stem from structural factors such as government policy and hostile health care environments, as well as community and interpersonal factors such as social discrimination and rejection by families [12]. Such structural, community and interpersonal factors can contribute to a delay in accessing gender-affirming care $[29,30]$. TGD people who belong to racial and ethnic minority groups face even more challenges [31]. Intersectionality acknowledges that identity is multidimensional and is impacted on by historical, structural, and cultural factors [32, 33]. Ng [33] eloquently explains that "Practicing medicine through the lens of intersectionality proactively considers patients' diverse identities and how the sociocultural factors associated with membership in multiple minority groups can affect their health risks and health care experiences, and ultimately health decision making and health outcomes" [33]. It is thus important to keep in mind that despite a shared marginalised identity, TGD people are not a homogenous group, and that sub-groups and individuals may have different health care needs.

There are specific areas in which gender identityrelated health disparities have been researched. In the section that follows, we will discuss mental health, Human Immunodeficiency Virus (HIV), violence and victimisation. This evidence on health disparities shows that there 
are specific gender identity-related issues that health professionals need to know about and that should be included in health science curricula.

\section{Mental health}

A review of the health burden and needs of TGD populations globally reports that there is a significant mental health burden [12]. For example, estimates of depression prevalence were as high as $63 \%$ in a United States of America (USA) sample of 230 TGD women [34]. An Australian survey of 859 TGD young people found that $74.6 \%$ of participants had a diagnosis of depression and $72.2 \%$ an anxiety disorder. In this study, the incidence of self-harm was 79.7 , and $48.1 \%$ of participants reported a suicide attempt in the past [35]. The authors point out that "the higher frequency of mental health difficulties than the general population is not because an individual identifies as TGD. Rather, these difficulties are largely caused by external factors - in other words, how the world perceives and treats transgender people" [35]. To make sense of the high rate of attempted suicides by TGD people, experiences of rejection and discrimination need to be considered as a key factor [36].

Meyer has described the concept of minority stress in LGB persons - explaining that "stigma, prejudice, and discrimination create a hostile and stressful social environment that causes mental health problems" [37]. Hendricks and Testa framed minority stress as a concept in TGD people [38], by applying the factors described by Meyer: "prior discrimination or victimization, expectations of future victimization or rejection, internalized transphobia, and resilience" [37, 38]. Firstly, the external events that impact on someone's life as a result of their minority status such as discrimination and threats to their safety can negatively affect their mental health. The second factor is the anticipation and expectation that external stressful events will occur, leading to heightened vigilance. The negative expectations themselves can create distress for the person. The third factor is internalized transphobia, which can negatively affect someone's ability to cope with external stressful events and ultimately reduces their resilience. This resonates with the description of TGD stigma by White Hughto, Reisner and Pachankis [39] as operating at structural, interpersonal and individual levels.

Importantly, Meyer [37] points out that not all of the effects of minority stress are negative, as members of minority groups can develop resilience. Hendricks and Testa [38] describe "group-level coping" in TGD persons, when they engage with other members of their minority group. Trans-specific social networks can create a supportive community that can buffer the effects of discrimination and violence. Riggs and Treharne (2017) add the theoretical framework of decompensation, described as "[ceasing] being able to compensate, [ceasing] being able to make up for the daily discrimination, [ceasing] being able to prop oneself up in the face of ideologies that render one's existence unintelligible" [40]. This framework emphasises the need to challenge ideology and social norms that cause decompensation, as opposed to only focusing on individual resilience [40, 41]. Unfortunately, due to the lack of health professionals' knowledge, and implicit or explicit prejudicial attitudes, the healthcare system often perpetuates the discrimination and marginalisation of TGD people within wider society, and this environment adds to, rather than alleviates, gender identity-related minority stress [42].

A study that compared the mental health of socially transitioned TGD children who are supported in their gender identity to that of cisgender children, found that depression rates were similar in both groups, and only slightly elevated anxiety rates were found amongst the TGD children [43]. Social transition can thus be regarded as a buffer against poor mental health. While there is a high prevalence of mental health challenges, there is evidence that gender-affirming hormone treatment can improve mental health [44-46].

\section{HIV}

TGD women are disproportionately affected by HIV and other sexually transmitted infections [12]. A systematic review reported an odds ratio of 48.8 for HIV infection in TGD women compared with all adults of reproductive age across 15 countries [47]. A study of 230 TGD women in New York found that "gender abuse predicted depressive symptoms, and gender abuse combined with depressive symptoms predicted both high-risk sexual behaviour (unprotected receptive anal intercourse) and HIV" [34].

\section{Violence and victimisation}

A high burden of violence and victimisation experiences in TGD people have been documented in research across the globe [12]. A WHO review reported that a high proportion of gender minority people experienced physical and sexual violence, motivated by bias or hate based on their gender identity [48]. This review found that "the prevalence of physical violence in TGD people ranged from $11.8 \%$ to $68.2 \%$ and sexual violence $7.0 \%$ to 49.1\%". A comparative study on being TGD in Europe that included 28 countries, analysed data from 6579 respondents [49]. While $54 \%$ of respondents stated that they had been discriminated against during the last year, $22 \%$ felt discriminated against in a health care setting [42]. A study of the effect of violence on TGD people, with a sample of 179 TGD women and 92 TGD men in Virginia [50] found that those who had experienced physical and/or sexual violence were significantly more likely to report a history of suicide attempts, alcohol 
abuse and illicit substance use. TGD individuals who present visibly as gender nonconforming have been shown to face even more discrimination compared to their gender conforming counterparts [51] and a UK study found that respondents currently undergoing a process of transition were significantly more likely to have reported experiencing physical and sexual harassment, compared to those who were proposing to undergo or had already undergone a process of transition [52]. In a survey of attitudes towards homosexuality and gender non-conformity in South Africa, $1 \%$ of respondents $(n=3079)$ agreed to the statement "I have physically hurt women who dressed and acted like men in public in the past year", and between 6.2 and $7.4 \%$ of South Africans indicated that they might use violence against gender non-conforming people in the future [53]. Violence towards trans people is not only institutional and societal, but can be experienced within families, as described by Rogers [54] who found that family perceptions of shame and stigma can lead to transphobic 'honour-based' abuse.

\section{Do TGD people experience stigma and discrimination in health care settings?}

TGD persons are more likely to face barriers when they try to access appropriate health care, compared to their cisgender peers [55]. There is evidence in the literature that transphobia in the health sector can lead to experiences of discrimination and stigma. Several USA studies of TGD persons reported negative health care experiences and found that knowledge gaps and discrimination contributed to a disparity in health care delivery [56-60]. A Canadian study of 923 TGD youth found that they described many past negative care encounters, with "uncomfortable and frustrating encounters with doctors" [61]. Two qualitative Swedish studies $[62,63]$ found that TGD persons experience estrangement in health care settings, due to lack of knowledge among health professionals. Participants described being treated as different, "to be regarded as a monkey in a cage appears to be very strenuous" [54]. In a UK study, $29 \%$ of respondents $(n=411)$ felt that their gender identity was not validated as genuine in mental health settings and qualitative data indicated that some trans people felt that at gender identity clinics, the clinical sessions "ran counter to the preservation of their dignity and human rights" [64]. Negative experiences of gender diverse Australians were reported as physical healthcare being "invasive and sometimes abusive" [65]. There is limited research about TGD people published from the African continent and Asia. Qualitative studies in South Africa have reported that many of the TGD persons interviewed had experienced health workers as being discriminatory and hostile [66-68].
Negative health care experiences can be the result of subtle, apparently insignificant features of health care spaces and interpersonal interactions called microaggressions $[69,70]$. Nadal et al. [70] define microaggressions as "subtle forms of discrimination, often unconscious or unintentional, that communicate hostile or derogatory messages, particularly to and about members of historically marginalized social groups" [70]. Although originally used to describe racial microaggressions [71], the theory was expanded to include other marginalised groups, including TGD people [70]. Health care spaces and providers often convey cisnormative microaggressions, which communicate to TGD people that "their identities, experiences, and relationships are abnormal, pathological, unexpected, unwelcome, or shameful" [69]. An example would be misgendering, a term meaning patients were misidentified or referred to by the incorrect pronoun [72].

\section{Gender and sexuality in health science education in relation to sexual and gender minority groups}

Much of the negative attitudes of health professionals toward sexual and gender minority groups may originate from wider societal homophobia and transphobia. The paucity of education about LGBTQ health allows these notions to go unchallenged, thereby maintaining the heteronormative and cisnormative culture in health facilities [73]. In health sciences, the dominant pedagogical approach to sexuality has been biomedical. This emphasis leaves little space to interrogate the constructions of gender and sexuality through social dynamics [74]. Müller \& Crawford-Browne [75] argue that "biomedical discourse bases its authority on empirical evidence - 'objective' scientific facts - and constructs people's bodies as results of biological processes and determinations". This biomedical approach makes it difficult to situate these bodies in their social context. Although more emphasis has been placed in recent years on the biopsychosocial approach, the health sciences have traditionally regarded bodies through a positivist lens that limits the extent to which socially constructed identities can be acknowledged [75].

It is essential for health sciences education to include critical reflection on the historical and contemporary hegemony of heteronormative and cisnormative discourses. This can assist both students and teachers to identify their discomfort with LGBTQ patients and reflect on how this could have originated in oppressive structures [76]. This can begin to address the root causes of the alienation experienced by TGD persons in health care settings, rather than just treating the symptoms.

\section{What are the gaps in curricula?}

Several studies have been published internationally that describe the gaps in medical curricula. In a study of 
undergraduate medical education in the USA and Canada in 2009-2010, only $30.3 \%$ of the 150 medical schools surveyed reported teaching about gender transitioning [77]. Gaps in residency programs in the USA have been described for Emergency Medicine [78], Urology [79] and Plastic surgery [80]. A survey of 15 Australian and New Zealand medical schools found that teaching about gender and gender identity is varied across schools, with seven respondents (47\%) unsure about what is taught [81]. In a United Kingdom study of medical students, participants were particularly unconfident on TGD health terminology and $72.9 \%$ felt "very unconfident" or "unconfident" deciding into which ward TGD patients should be admitted [82]. Canadian qualitative studies found a reported lack of knowledge regarding TGD health among family physicians [83] and mental health care providers [84]. A Canadian qualitative analysis of physician-side barriers to providing health care for TGD patients aptly titled "Completely out-at-sea with two-gender medicine", found that a lack of knowledge made the clinical management of TGD patients more complicated [1]. In a survey of emergency medicine physicians in the USA, $82.5 \%$ reported that they did not receive formal training on TGD health care although $88 \%$ reported caring for this population [85]. A study of speech-language pathologists in four countries found that although TGD communication is within their scope of practice, $47 \%$ of respondents indicated that this was not included in their master's curriculum [86]. A study of health professions education in South Africa and Malawi [87] found that there is little formal inclusion of LGBTQ health topics in nursing and medical curricula, and that educators who do teach LGB health topics reported doing so because "they felt personally compelled to include them", not because this was supported or mandated institutionally. Topics related to TGD health and differences in sex characteristics were not covered by any of the participating educators [87].

An ethical discussion by Tomson [88] that compares the gatekeeping model and the informed-consent model of providing gender-affirming care provides an important perspective of how lack of knowledge of health professionals can lead to unethical care [88]. In the gatekeeping model, service providers make the assessment of whether or not a patient should be allowed access to genderaffirming care. Tomson [88] argues that this violates the principle of respect for autonomy. In contrast, the principle of autonomy is upheld by the informed-consent model. In this model, treatment is a cooperative effort between the patient and provider where well informed patients are the primary decision makers about their care [89]. A patient's ability to make informed decisions about their health, e.g. starting hormone treatment, is enhanced by thorough education [89]. Furthermore, Tomson [88] argues that "since access to medical transition improves outcomes (particularly suicide risk) for TGD patients, limiting access to these interventions can be seen as harmful in and of itself, and as such, is a violation of the principle of non-maleficence". When patients can decide on their own health care in an informed consent model, without factors such as race, social class or finance creating barriers to access, this promotes equity and fairness and upholds the principle of justice [88]. Although the informed consent model is used in some clinics [90], the gatekeeping model is still the mainstream treatment paradigm in many settings [91], which has implications for the role of health science education to promote an ethical model of care.

\section{What educational interventions have been described?}

A recent scoping review of improving medical students' and residents' training and awareness of TGD health care found that consensus is lacking on exactly which educational interventions to use to address this topic [92]. Another review focusing on curricular initiatives that enhance student knowledge and perceptions of sexual and gender minority groups concluded that "multi-modal approaches that encouraged awareness of one's lens and privilege in conjunction with facilitated communication seemed the most effective" [93]. The literature supports a shift toward longitudinally integrated and clinical skills based pedagogical interventions [92]. A $90 \mathrm{~min}$ workshop for psychiatry residents at Columbia university, USA, produced significant shortterm increases in resident professionalism toward TGD patients [94]. However, on 90-day follow-up, this study did not find any statistically significant differences in perceived empathy, knowledge, comfort, and motivation for future learning, compared to baseline [94]. This highlights the limitations of one-time interventions and call for longitudinal programming to produce more durable improvements. Stroumsa et al. [95] caution that transphobia needs to be addressed specifically as a potential barrier to improved knowledge. Their study did not find any association between increased hours of education and improved knowledge, but found a negative association between transphobia and provider knowledge [95]. Gamble Blakey and Treharne [96] emphasize values cultivation as a starting point in educating about TGD healthcare, and argue that simply adding curricular content about gender-affirming care may not result in significant learning as this requires a sensitive and specific pedagogic discourse around values [97].

The Association of American Medical Colleges published an extensive resource for medical educators in 2014, titled "Implementing Curricular and Institutional Climate Changes to Improve Health Care for Individuals Who Are LGBT, Gender Nonconforming, or Born with 
DSD" [98]. It discusses the role of medical education and health care professionals in eliminating health disparities, lists professional competency objectives as well as discusses integrating competencies into medical school curricula [98]. This publication has been described by Donald et al. [29] as "representing a new frontier in medical education that attempts to redefine health to be inclusive of sexual orientation, gender identity, gender expression, and sex development-four intrinsic components of personhood" [29]. In the chapter on Trauma and Resilience, the authors emphasize that competence in providing care to diverse individuals requires more than an understanding of the causes of health disparities and to know to avoid microaggressions, making assumptions or discriminatory remarks: "It is imperative that health care providers learn how to promote resilience in the lives and families of individuals who are members of these groups so as to mitigate the effects of real and perceived trauma on risk behaviours and adverse health outcomes" [98].

There has been a recent proliferation of publications in professional journals to educate medical practitioners already in practice. These include the specialities of Endocrinology [99], Paediatrics [100-102]; Family Medicine [103, 104], Gynaecology [105], Psychiatry [106], Surgery $[107,108]$ and Anaesthesia [109]. Free e-learning courses have been developed such as "Primary Health Care for Trans, Gender Diverse \& Non-binary People" [110] and "Caring for Gender Nonconforming young people" [111].

\section{Argument for including TGD health care in curricula}

Winter argues that because "primary care is the most common point of contact that TGD people have with the health system, effective training for primary care providers through medical education and continuing professional development, is needed" [112]. Primary care providers can evaluate gender dysphoria and manage applicable hormone therapy [104]. In much of the world, specialist services for gender-affirming health care are not widely available, which reinforces the need for the training of primary care providers.

DasGupta and colleagues argue that incorporating social justice into the education of medical professionalism is critical [113]. A global consensus document on the social accountability of medical schools [114] includes statements that resonate with the need to include gender-affirming health in curricula, such as: "The medical school recognizes the various social determinants of health - and directs its education, research and service delivery programs accordingly," and "the medical school recognizes the local community as a primary stakeholder and shares responsibility for a comprehensive set of health services to a defined population in a given geographical area, consistent with values of quality, equity, relevance". A South African report, "Reconceptualising Health Professions Education in South Africa" [115] states that "the ultimate goal of health professions education is to produce knowledgeable, competent, relevant, socially accountable health care professionals capable of confidently and collaboratively promoting health and addressing the country's burden of disease across the continuum of health care in the context of quality universal health coverage". To be socially accountable, medical educators need to include the health needs of TGD people in medical curricula $[29,116]$. The ethical imperative of the medical profession to reduce health care disparities and practice within the health care values of social justice, cultural humility and humanism has been highlighted by medical educators and researchers [98]. The World Medical Association (WMA) adopted a statement on TGD people in 2015 [117]. In this document, the WMA calls "for the provision of appropriate expert training for physicians at all stages of their career to enable them to recognise and avoid discriminatory practises, and to provide appropriate and sensitive transgender health care" [117].

\section{Conclusion}

Whereas ideally gender should be viewed as a spectrum, and gender diversity as part of the diversity of humanity, in reality TGD persons often have very difficult lives due to not fitting into society's cisnormative expectations [11, 12]. This leads to significant gender identity-related health disparities in the areas of mental health [34, 35], HIV risk [47], as well as violence and discrimination [48]. TGD people often experience stigma and discrimination in health care settings, which is a barrier to access to care [55]. Health professional attitudes and knowledge gaps contribute to and exacerbate these health disparities [56, 57]. The minority stress model describes how external stressors such as transphobic experiences can lead to anticipation of bad experiences, which can lead to avoidance of accessing health care [37, 38]. Several studies have described the gaps in undergraduate medical training $[77,81,82]$ as well as residency training [78-80]. The gatekeeping model, where service providers decide who can access care, violates the ethical principle of respect for autonomy, while the informed-consent model upholds autonomy by empowering patients to make their own health care decisions [88]. As health science educators, representing a profession that has pathologized [10, 25], and continues to pathologize TGD identities [15], we have an ethical duty to include gender-affirming health in health science curricula $[98,116$, 117] in order to prevent harm to TGD patients that our students will provide care for in the future.

\section{Abbreviations}

DSM: Diagnostic and Statistical Manual of Mental Disorders; HIV: Human Immunodeficiency Virus; ICD: International Classification of Disease; 
LGB: Lesbian, gay, bisexual; LGBT: Lesbian, gay, bisexual, transgender; LGBTQ: Lesbian, gay, bisexual, transgender, queer; SDOH: Social determinants of health; TGD: Trans and gender diverse; USA: United States of America; WHO: World Health Organisation; WMA: World Medical Association

\section{Acknowledgements}

We would like to thank all reviewers for helpful suggestions and literature, especially reviewers 1 and 3 for pointing out our own unconscious normativities, which prompted us to reword our definitions related to transgender and cisgender people.

\section{Authors' contributions}

All authors conceptualised the topic and outline of the work together and had lively debates around the key concepts. EDV wrote the initial draft, AM and HK made substantial contributions to the draft and the manuscript in subsequent revisions. All authors read and approved the final manuscript.

\section{Funding}

Not applicable

\section{Availability of data and materials}

All data generated or analysed during this study are included in this published article

\section{Ethics approval and consent to participate}

Not applicable

\section{Consent for publication}

Not applicable

\section{Competing interests}

The authors declare that they have no competing interests.

\section{Author details}

'School of Public Health and Family Medicine, University of Cape Town, Cape Town, South Africa. ${ }^{2}$ Department of Health and Rehabilitation Sciences, University of Cape Town, Cape Town, South Africa. ${ }^{3}$ Gender, Health and Justice Research Unit, University of Cape Town, Cape Town, South Africa.

Received: 13 May 2019 Accepted: 7 February 2020

Published online: 14 February 2020

\section{References}

1. Snelgrove JW, Jasudavisius AM, Rowe BW, Head EM, Bauer GR. "Completely out-at-sea" with "two-gender medicine": a qualitative analysis of physicianside barriers to providing healthcare for transgender patients. BMC Health Serv Res. 2012;12(1):110.

2. Oliphant J, Veale J, MacDonald J, Carroll R, Johnson R, Harte M, et al. Guidelines for gender affirming healthcare for gender diverse and transgender children, young people and adults in Aotearoa, New Zealand. N Z Med J. 2018;131(1487):86-96.

3. Center of Excellence for Transgender Health. Guidelines for the primary and gender-affirming care of transgender and gender nonbinary people. In: Deutsch MB, editor. University of California, San Francisco. San Francisco: Center of Excellence for Transgender Health; 2016.

4. Reisner SL, Radix A, Deutsch MB. Integrated and gender-affirming transgender clinical care and research. J Acquir Immune Defic Syndr. 2016; 72:S235-42.

5. Ard KL, Makadon HJ. Improving the health care of lesbian, gay, bisexual and transgender people. Boston: The Fenway Institute; 2012. https://www. lgbtagingcenter.org/resources/pdfs/12-054_LGBTHealtharticle_v3_07-09-12. pdf. Accessed 21 Jan 2018

6. National LGBT Health Education Center. Glossary of LGBT terms for health care teams. Boston: National LGBT Health Education Center; 2017. p. 1-7. https://www.lgbthealtheducation.org/wp-content/uploads/2018/03/ Glossary-2018-English-update-1.pdf. Accessed 26 Mar 2018

7. Bourns A. Guidelines and protocols for hormone therapy and primary health care for trans clients. 2nd ed. Toronto: Sherbourne Health Centre; 2015. https://www.rainbowhealthontario.ca/wp-content/uploads/ woocommerce uploads/2015/04/SHC-Protocols-for-Hormone-TherapyFinal1.pdf. Accessed 26 Mar 2018
8. Psychological Society of South Africa. Practice guidelines for psychology professionals working with sexually and gender-diverse people. 1st ed. Victor CJ, Nel JA, editors. Johannesburg: Psychological Society of South Africa; 2017. http://www.psyssa.com. Accessed 22 Apr 2018

9. Worthen MGF. Hetero-cis-normativity and the gendering of transphobia. Int J Transgenderism. 2016;17(1):31-57.

10. Müller A. Health for all? Sexual orientation, gender identity, and the implementation of the right to access to health care in South Africa. Heal Hum Rights An Int J. 2016;18(2):195-208.

11. Noonan EJ, Sawning S, Combs R, Weingartner LA, Martin LJ, Jones VF, et al. Engaging the transgender community to improve medical education and prioritize healthcare initiatives. Teach Learn Med. 2018;30(2):119-32.

12. Reisner SL, Poteat T, Keatley JA, Cabral M, Mothopeng T, Dunham E, et al. Global health burden and needs of transgender populations: a review. Lancet. 2016;388(10042):412-36.

13. Holthouser A, Sawning S, Leslie KF, Faye Jones V, Steinbock S, Noonan EJ, et al. eQuality: a process model to develop an integrated, comprehensive medical education curriculum for LGBT, gender nonconforming, and DSD health. Med Sci Educ. 2017;27(2):371-83.

14. Beek TF, Cohen-kettenis PT, Kreukels BPC. Gender incongruence / gender dysphoria and its classification history. Int Rev Psychiatry. 2016; 28(1):5-12.

15. Polderman TJC, Kreukels BPC, Irwig MS, Beach L, Chan YM, Derks EM, et al. The biological contributions to gender identity and gender diversity: bringing data to the table. Behav Genet. 2018;48(2):95-108.

16. King M. Treatments of homosexuality in Britain since the 1950s - an oral history: the experience of professionals. BMJ. 2004;328(7437):429-0.

17. Mendos LR. State-sponsored homophobia. Geneva: Switzerland; 2019. https://ilga.org/state-sponsored-homophobia-report. Accessed 2 May 2019

18. American Psychiatric Association. Diagnostic and statistical manual of mental disorders. 5th ed. Arlington: American Psychiatric Association; 2013.

19. Kara S. Gender is not an illness. How pathologizing trans people violates international human rights law: GATE; 2017. https://transactivists.org/ category/campaigns-advocacy/publications/. Accessed 3 May 2019

20. Davy Z, Sørlie A, Schwend AS. Democratising diagnoses? The role of the depathologisation perspective in constructing corporeal trans citizenship. Crit Soc Policy. 2018;38(1):13-34.

21. World Health Organization (WHO). ICD-10 International statistical classification of diseases and related health problems 10th Revision. Geneva: World Health Organization; 1992.

22. Beek TF, Cohen-Kettenis PT, Bouman WP, De Vries ALC, Steensma TD, Witcomb GL, et al. Gender incongruence of adolescence and adulthood: acceptability and clinical utility of the world health organization's proposed ICD-11 criteria. PLoS One. 2016;11(10):1-21.

23. World Health Organization (WHO). ICD-11: Classifying disease to map the way we live and die. 2018. https://www.who.int/news-room/spotlight/ international-classification-of-diseases. Accessed 25 July 2018.

24. World Health Organisation. World Health Assembly Update, 25 May 2019. 2019. https://www.who.int/news-room/detail/25-05-2019-world-healthassembly-update. Accessed 3 June 2019.

25. Drescher J, Cohen-Kettenis P, Winter S. Minding the body: situating gender identity diagnoses in the ICD-11. Int Rev Psychiatry. 2012;24(6):568-77.

26. McLachlan C. Que(e) ring trans and gender diversity. South African J Psychol. 2019;49(1):7-9.

27. WHO. About social determinants of health: WHO; 2017. http://www.who.int/ social_determinants/sdh_definition/en/. Accessed 22 Apr 2018

28. Pega F, Veale JF. The case for the world health organization's commission on social determinants of health to address gender identity. Am J Public Health. 2015;105(3):e58-62

29. Donald CA, DasGupta S, Metzl JM, Eckstrand KL. Queer frontiers in medicine. Acad Med. 2017:92(3):345-50.

30. Seelman KL, Colón-Diaz MJP, LeCroix RH, Xavier-Brier M, Kattari L. Transgender noninclusive healthcare and delaying care because of fear: connections to general health and mental health among transgender adults. Transgender Heal. 2017;2(1):17-28.

31. Kattari SK, Walls NE, Whitfield DL, Langenderfer-Magruder L. Racial and ethnic differences in experiences of discrimination in accessing health services among transgender people in the United States. Int J Transgenderism. 2015;16(2):68-79.

32. Eckstrand $\mathrm{KL}$, Eliason J, St Cloud T, Potter J. The priority of intersectionality in academic medicine. Acad Med. 2016;91(7):904-7. 
33. $\mathrm{Ng} \mathrm{HH}$. Intersectionality and shared decision making in LGBTQ health. LGBT Heal. 2016;3(5):325-6.

34. Nuttbrock L, Bockting W, Rosenblum A, Hwahng S, Mason M, Macri M, et al. Gender abuse, depressive symptoms, and HIV and other sexually transmitted infections among male-to-female transgender persons: a threeyear prospective study. Am J Public Health. 2013;103(2):300-7.

35. Strauss P, Cook A, Winter S, Watson V, Wright Toussaint DLA. Trans pathways: the mental health experiences and care pathways of trans young people - summary of results. Perth; 2017. https://www.telethonkids.org.au/ transpathways. Accessed 22 Apr 2018

36. Klein A, Golub SA. Family rejection as a predictor of suicide attempts and substance misuse among transgender and gender nonconforming adults. LGBT Heal. 2016;3(3):193-9.

37. Meyer $\mathbf{H}$. Prejudice, social stress, and mental health in lesbian, gay, and bisexual populations: conceptual issues and research evidence. Psychol Bull. 2003;129(5):674-97.

38. Hendricks ML, Testa RJ. A conceptual framework for clinical work with transgender and gender nonconforming clients: an adaptation of the minority stress model. Prof Psychol Res Pract. 2012:43(5):460-7.

39. White Hughto JM, Reisner SL, Pachankis JE. Transgender stigma and health: a critical review of stigma determinants, mechanisms, and interventions. Soc Sci Med. 2015;147:222-31.

40. Riggs DW, Treharne GJ. Decompensation: a novel approach to accounting for stress arising from the effects of ideology and social norms. J Homosex. 2017;64(5):592-605.

41. Riggs DW, Ansara GY, Treharne GJ. An evidence-based model for understanding the mental health experiences of transgender Australians. Aust Psychol. 2015;50(1):32-9.

42. Jacob M, Cox SR. Examining transgender health through the international classification of functioning, disability, and health's (ICF) contextual factors. Qual Life Res. 2017;26(12):3177-85.

43. Olson KR, Durwood L, DeMeules M, McLaughlin KA. Mental health of transgender children who are supported in their identities. Pediatrics. 2015; 137(3):e20153223.

44. Colizzi M, Costa R, Todarello O. Transsexual patients' psychiatric comorbidity and positive effect of cross-sex hormonal treatment on mental health: results from a longitudinal study. Psychoneuroendocrinology. 2014;39(1):65-73.

45. Wilson EC, Chen YH, Arayasirikul S, Wenzel C, Raymond HF. Connecting the dots: examining transgender women's utilization of transition-related medical care and associations with mental health, substance use, and HIV. J Urban Health. 2015;92(1):182-92.

46. Keo-Meier CL, Herman LI, Reisner SL, Pardo ST, Sharp C, Babcock JC. Testosterone treatment and MMPI-2 improvement in transgender men: a prospective controlled study. J Consult Clin Psychol. 2015;83(1):143-56.

47. Baral SD, Poteat T, Strömdahl S, Wirtz AL, Guadamuz TE, Beyrer C. Worldwide burden of HIV in transgender women: a systematic review and meta-analysis. Lancet Infect Dis. 2013;13(3):214-22

48. Blondeel K, de Vasconcelos S, García-Moreno C, Stephenson R, Temmerman $\mathrm{M}$, Toskin I. Violence motivated by perception of sexual orientation and gender identity: a systematic review. Bull World Health Organ. 2018 ;96(1): 29-41L. https://doi.org/10.2471/BLT.17.197251 Accessed 10 Feb 2018.

49. European Union Agency for Fundamental Rights. Being trans in the EU comparative analysis of EU LGBT survey data. 2014. papers3://publication/ doi/10.2811/92683. Accessed 22 Apr 2018.

50. Testa R, Sciacca LM, Wang F, Hendricks ML, Goldblum P, Bradford J, et al. Effects of violence on transgender people. Prof Psychol Res Pract. 2012;43(5):452-9.

51. Miller LR, Grollman EA. The social costs of gender nonconformity for transgender adults: implications for discrimination and health. Sociol Forum. 2015:30(3):809-31.

52. Ellis SJ, Bailey L, McNeil J. Transphobic victimisation and perceptions of future risk: a large-scale study of the experiences of trans people in the UK. Psychol Sex. 2016;7(3):211-24.

53. Sutherland C, Roberts B, Gabriel N, Struwig JGS. Progressive prudes - a survey of attitudes towards homosexuality \& gender non-conformity in South Africa. Pretoria; 2016. http://www.hsrc.ac.za/en/research-data/view/ 8245. Accessed 10 Feb 2018

54. Rogers M. Transphobic 'honour'-based abuse: a conceptual tool. Sociology 2017:51(2):225-40.

55. Müller A. Scrambling for access: availability, accessibility, acceptability and quality of healthcare for lesbian, gay, bisexual and transgender people in South Africa. BMC Int Health Hum Rights. 2017;17(16):1-10.
56. Grant JM, Mottet L a, Tanis J, Harrison J, Herman $J$, Keisling M. Injustice at every turn - a report of the national transgender discrimination survey. Washington; 2011. http://www.thetaskforce.org/static_html/downloads/ reports/reports/ntds_summary.pdf. Accessed 11 Feb 2018

57. Jaffee KD, Shires DA, Stroumsa D. Discrimination and delayed health care among transgender women and men implications for improving medical education and health care delivery. Med Care. 2016;54(11):1010-6.

58. James SE, Herman JL, Rankin S, Keisling M, Mottet L, Anafi M'a. The report of the 2015 U.S. transgender survey. Washington, DC; 2016. https://www. transequality.org/sites/default/files/docs/USTS-Full-Report-FINAL.PDF. Accessed 18 Mar 2018

59. Kosenko K, Rintamaki L, Raney S, Maness K. Transgender patient perceptions of stigma in health care contexts. Med Care. 2013;51(9):819.

60. Samuels EA, Tape C, Garber N, Bowman S, Choo EK. "Sometimes you feel like the freak show": a qualitative assessment of emergency care experiences among transgender and gender-nonconforming patients. Ann Emerg Med. 2018;11(2):170-182.e1.

61. Clark BA, Veale JF, Greyson D, Saewyc E. Primary care access and foregone care: a survey of transgender adolescents and young adults. Fam Pract. 2017. https://doi.org/10.1093/fampra/cmx112.

62. Lindroth M. 'Competent persons who can treat you with competence, as simple as that' - an interview study with transgender people on their experiences of meeting health care professionals. J Clin Nurs. 2016;25(2324):3511-21.

63. von Vogelsang AC, Milton C, Ericsson I, Strömberg L. 'Wouldn't it be easier if you continued to be a guy?' - a qualitative interview study of transsexual persons' experiences of encounters with healthcare professionals. J Clin Nurs. 2016:25(23-24):3577-88.

64. Ellis SJ, Bailey L, McNeil J. Trans people's experiences of mental health and gender identity services: a UK study. J Gay Lesbian Ment Heal. 2015;19(1):4-20.

65. Riggs DW, Coleman K, Due C. Healthcare experiences of gender diverse Australians: a mixed-methods, self-report survey. BMC Public Health. 2014; 14(1):1-5

66. Sanger N. Young and transgender: understanding the experiences of young transgender persons in educational institutions and the health sector in South Africa A. Cape Town: Gender DynamiX; 2014.

67. Stevens M. Transgender access to sexual health services in South Africa : findings from a key informant survey. Cape Town; 2012. https:// genderdynamix.org.za/wp-content/uploads/2012/10/Transgender-access-tosexual-health-services-in-South-Africa.pdf?x91330. Accessed 10 Feb 2018

68. Newman-Valentine D, Duma S. Injustice to transsexual women in a heteronormative healthcare system. Afr J Prim Heal Care Fam Med. 2014;6(1):1-5.

69. Dean MA, Victor E, Guidry-Grimes L. Inhospitable healthcare spaces: why diversity training on LGBTQIA issues is not enough. J Bioeth Inq. 2016;13(1): $557-70$

70. Nadal KL, Whitman CN, Davis LS, Erazo T, Davidoff KC. Microaggressions toward lesbian, gay, bisexual, transgender, queer, and genderqueer people: a review of the literature. J Sex Res. 2016;53(4-5):488-508.

71. Sue DW, Capodilupo CM, Torino GC, Bucceri JM, Holder AMB, Nadal KL, et al. Racial microaggressions in everyday life: implications for clinical practice. Am Psychol. 2007;62(4):271-86.

72. Nadal KL, Skolnik A, Wong Y. Interpersonal and systemic microaggressions toward transgender people: implications for counseling. J LGBT Issues Couns. 2012 Jan;6(1):55-82.

73. Meer T, Müller A. "They treat us like we're not there": queer bodies and the social production of healthcare spaces. Health Place. 2017;45(March):92-8.

74. Bennett J, Reddy V. "Feeling the disconnect": teaching sexualities and gender in South African higher education. Fem Africa. 2007:43-62.

75. Müller A, Crawford-Browne S. Challenging medical knowledge at the source - attempting critical teaching in the health sciences briefing challenging medical knowledge at the source - attempting critical teaching in the health sciences. Agenda. 2013:27(4):25-34.

76. Harbin A, Beagan B, Goldberg L. Discomfort, judgment, and health care for queers. J Bioeth Inq. 2012;9(2):149-60.

77. Obedin-Maliver J, Goldsmith ES, Stewart L, White W, Tran E, Brenman S, et al. Lesbian, gay, bisexual, and transgender-related content in undergraduate medical education. Jama. 2011;306(9):971-7.

78. Moll J, Krieger P, Moreno-Walton L, Lee B, Slaven E, James T, et al. The prevalence of lesbian, gay, bisexual, and transgender health education and training in emergency medicine residency programs: what do we know? Acad Emerg Med. 2014;21(5):608-11. 
79. Dy GW, Osbun NC, Morrison SD, Grant DW, Merguerian PA. Exposure to and attitudes regarding transgender education among urology residents. J Sex Med. 2016 Oct;13(10):1466-72.

80. Morrison SD, Dy GW, Chong HJ, Holt SK, Vedder NB, Sorensen MD, et al. Transgender-related education in plastic surgery and urology residency programs. J Grad Med Educ. 2017;9(2):178-83.

81. Sanchez AA, Southgate E, Rogers G, Duvivier RJ. Inclusion of lesbian, gay, bisexual, transgender, queer, and intersex health in Australian and New Zealand Medical Education. LGBT Heal. 2017;4(4):Igbt.2016.0209.

82. Parameshwaran V, Cockbain BC, Hillyard M, Price JR. Is the lack of specific lesbian, gay, bisexual, transgender and queer/questioning (LGBTQ) health care education in medical school a cause for concern? Evidence from a survey of knowledge and practice among UK medical students. J Homosex. 2017;64(3):367-81.

83. Beagan B, Fredericks E, Bryson M. Family physician perceptions of working with LGBTQ patients: physician training needs. Can Med Educ J. 2015;6(1): e14-22.

84. Rutherford K, Mcintyre J, Daley A, Ross LE. Development of expertise in mental health service provision for lesbian, gay, bisexual and transgender communities. Med Educ. 2012;46(9):903-13.

85. Chisolm-Straker M, Willging C, Daul AD, Mcnamara S, Cham SS, Shattuck DG, et al. Transgender and gender-nonconforming patients in the emergency department: what physicians know, think, and do. Ann Emerg Med. 2018;71(2):183-188.e1.

86. Hancock A, Haskin G. Speech-language pathologists' knowledge and attitudes regarding lesbian, gay, bisexual, transgender, and queer (LGBTQ) populations. Am J Speech-Language Pathol. 2015;24(2):206-21.

87. Müller A, Daskilewicz K, Langen B, Odumosu O. These are the topics cannot run away from. Amsterdam: COC Netherlands; 2017.

88. Tomson A. Gender-affirming care in the context of medical ethics gatekeeping $\vee$. informed consent. S Afr J Bioeth Law. 2018;11(1):24-8.

89. Cundill P, Wiggins J. Protocols for the initiation of hormone therapy for trans and gender diverse patients. Melbourne: Equinox Gender Diverse Health Centre; 2017. https://thorneharbour.org/documents/108/b3e096c2equinox-informed-consent-guidelines.pdf. Accessed 10 Oct 2019

90. Deutsch MB. Use of the informed consent model in the provision of crosssex hormone therapy: a survey of the practices of selected clinics. Int J Transgenderism. 2012;13:140-6.91.

91. Schulz SL. The informed consent model of transgender care: an alternative to the diagnosis of gender dysphoria. J Humanist Psychol. 2018;58(1):72-92.

92. Dubin SN, Nolan IT, Greene RE, Radix AE, Morrison SD. Transgender health care: improving medical students' and residents' training and awareness. Adv Med Educ Pract. 2018:9:377-91.

93. Desrosiers J, Wilkinson T, Abel G, Pitama S. Curricular initiatives that enhance student knowledge and perceptions of sexual and gender minority groups: a critical interpretive synthesis. Can Med Educ J. 2016;7(2):e121-38.

94. Kidd JD, Bockting W, Cabaniss DL, Blumenshine P. Special-"T" training: extended follow-up results from a residency-wide professionalism workshop on transgender health. Acad Psychiatry. 2016:40(5):802-6.

95. Stroumsa D, Shires DA, Richardson CR, Jaffee KD, Woodford MR Transphobia rather than education predicts provider knowledge of transgender health care. Med Educ. 2019;53:398-407.

96. Gamble Blakey A, Treharne GJ. Overcoming barriers to transgender healthcare education in Aotearoa New Zealand. New Zeal J Educ Stud. 2019;54(2):357-66.

97. Gamble Blakey A, Treharne GJ. Advancing transgender healthcare teaching in Aotearoa/New Zealand. N Z Med J. 2019;132(1491):104-6.

98. Association of American Medical Colleges. Implementing curricular and institutional climate changes to improve health care for individuals who are LGBT, gender nonconforming, or born with DSD, vol. 2. Washington, DC Association of American Medical Colleges; 2014. https://members.aamc.org/ eweb/upload/Executive\%20LGBT\%20FINAL.pdf. Accessed 11 Feb 2018

99. Hembree WC, Cohen-Kettenis PT, Gooren L, Hannema SE, Meyer WJ, Murad $\mathrm{MH}$, et al. Endocrine treatment of gender-dysphoric/gender-incongruent persons: an endocrine society clinical practice guideline. J Clin Endocrinol Metab. 2017;102(11):3869-903.

100. Rafferty J. Ensuring comprehensive care and support for transgender and gender-diverse children and adolescents. Pediatrics. 2018;142(4): e20182162. w.

101. Lopez X, Marinkovic M, Eimicke T, Rosenthal SM, Olshan JS. Statement on gender-affirmative approach to care from the pediatric endocrine society special interest group on transgender health. Curr Opin Pediatr. 2017;29(4): 475-80.

102. de Vries ALC, Klink D, Cohen-Kettenis PT. What the primary care pediatrician needs to know about gender incongruence and gender dysphoria in children and adolescents. Pediatr Clin N Am. 2016;63(6):1121-35.103.

103. Stumbar $\mathrm{S}$. The responsibility of family physicians to our transgender patients. Am Fam Physician. 2018;98(11):635.

104. Klein DA, Paradise SL, Goodwin ET. Caring for transgender and genderdiverse persons: what clinicians should know. Am Fam Physician. 2018; 98(11):645-53

105. Unger CA. Care of the transgender patient: the role of the gynecologist. Am J Obstet Gynecol. 2014;44(0):8371.

106. Wylie K, Barrett J, Besser M, Bouman WP, Bridgman M, Clayton A, et al. Good practice guidelines for the assessment and treatment of adults with gender dysphoria. Sex Relatsh Ther. 2014;29(2):154-214.

107. Berli JU, Knudson G, Fraser L, Tangpricha V, Ettner R, Ettner FM, et al. What surgeons need to know about gender confirmation surgery when providing care for transgender individuals. JAMA Surg. 2017;152(4):394.

108. Salibian AA, Levitt N, Zhao LC, Bluebond-Langner R. Preoperative and postoperative considerations in gender-affirming surgery. Curr Sex Heal Reports. 2018;10(3):186-95.

109. Etienne Tollinche L, Burrows Walters C, Radix A, Long M, Galante L, Garner Goldstein Z, et al. The perioperative care of the transgender patient. Anesth Analg. 2018;127(2):359-66.

110. McNair R, Andrews C. Primary health care for gender diverse young people. https://aelp.smartsparrow.com/v/open/f3xc2ipc. Accessed 7 Oct 2019.

111. GIRES. Caring for gender nonconforming young people - gender identity research \& education society. https://www.gires.org.uk/e-learning/caring-forgender-nonconforming-young-people/. Accessed 7 Oct 2019.

112. Winter S, Settle E, Wylie K, Reisner S, Cabral M, Knudson G, et al. Synergies in health and human rights: a call to action to improve transgender health. Lancet. 2016;388(10042):318-21.

113. DasGupta S, Fornari A, Geer K, Hahn L, Kumar V, Lee HJ, et al. Medical education for social justice: Paulo Freire revisited. J Med Humanit. 2006; 27(4):245-51.

114. Boelen C. Global consensus on social accountability of medical schools, vol. 23; 2010. http://healthsocialaccountability.org/. Accessed 11 Feb 2018

115. Academy of Science of South Africa. Reconceptualising health professions education in south Africa. Pretoria. 2018; https://doi.org/10.17159/assaf.2018/ 0021 . Accessed 23 July 2018.

116. Bonvicini KA. LGBT healthcare disparities: what progress have we made? Patient Educ Couns. 2017;100(12):2357-61.

117. World Medical Association. WMA statement on transgender people adopted by the 66th WMA general assembly. Moscow; 2015. http:// www.wma.net/en/30publications/10policies/t13/index.html. Accessed 20 Mar 2018

\section{Publisher's Note}

Springer Nature remains neutral with regard to jurisdictional claims in published maps and institutional affiliations.

Ready to submit your research? Choose BMC and benefit from:

- fast, convenient online submission

- thorough peer review by experienced researchers in your field

- rapid publication on acceptance

- support for research data, including large and complex data types

- gold Open Access which fosters wider collaboration and increased citations

- maximum visibility for your research: over $100 \mathrm{M}$ website views per year

At $\mathrm{BMC}$, research is always in progress.

Learn more biomedcentral.com/submissions 